\title{
Pilonidal sinus treatment: A new simplified technique; filling natal cleft with fasciofatty flap.
}

\author{
Mokhtar Abd Elrahman A Bahbah, MD; Ehab M Oraby, MD \\ Department of General Surgery, Benha University, Benha, Egypt.
}

\begin{abstract}
Background: Karydakis and Bascom designed new lines of surgical treatment of pilonidal sinus. Both of them share the principles of off-midline scar and cleft lift. The objective of this randomized clinical trial was to evaluate prospectively the outcome of adding few modifications to both techniques of Karydakis and Bascom.

Method: Sixty eight patients with pilonidal sinus were included in this study. After eradication of pathological tissues; the skin flap was created, a fasciofatty flap was everted to fill the natal cleft. On table removal of drain was done after sutureless collapse of wound cavity.

Results: The depth of the natal cleft showed a clear reduction. Four cases (5.9\%) developed seroma which required simple needle aspiration. All patients attended the follow up period with no recurrences.

Conclusion: This technique carries the simplicity with promising results. It helps in pathology eradication and reduction of natal cleft depth through a reliable filling with fasciofatty flap.

Key words: Pilonidal sinus, Karydakis-modification, Bascom modification, fascio-fatty flap, cleft lift, sutureless collapse of wound cavity.
\end{abstract}

\section{Introduction:}

Pilonidal sinus is a chronic subcutaneous abscess in the natal cleft, which spontaneously drains through its openings. The first documented case of pilonidal sinus was done by A.W. Anderson in his letter to the editor that appeared in an issue of the Boston Medical Surgical Journal of 1847, entitled "Hair Extracted from an Ulcer,". 1

In 1880, Hodges coined the term "pilonidal sinus" (pilus, meaning hair, and nidus, meaning nest) to describe the chronic sinus containing hair and found between the buttocks. He believed the condition was congenital in origin, representing an imperfect union of the lateral halves of the body. ${ }^{2}$

Buie called it "jeep disease" because of the frequent complaint among military personnel under stresses of driving trucks, tanks, and jeeps. ${ }^{3}$
During World War II seventy-nine thousand U.S. servicemen were hospitalized, each for an average 55 days, because of pilonidal disease and its treatment. 4

\section{Etiology and pathogenesis}

The origin of the pilonidal sinus has been a subject of interest for many years. The congenital theory was popular. ${ }^{5}$ Even in the modern era, the congenital theory still has its proponents. Lord reasoned that hairs in the pilonidal sinuses are identical in length, diameter, color, and orientation. He said, "It is hard to conceive any other theories that explain how hair can get into the pilonidal sinus from outside, which could possibly explain how 23 hairs should follow each other into a pilonidal sinus and each hair be identical in every respect to the last." 6

The acquired theory is now widely accepted. Its mechanism, however, is 
speculative and varied. Bascom believes the affected hair follicles become distended with keratin and subsequently infected, leading to folliculitis and the formation of an abscess that extends down into the subcutaneous fat. Once the abscess cavity is formed, hairs can enter through the tiny pit and lodge in the abscess cavity from the suction created by movement of the gluteal area. ${ }^{7}$

Karydakis, on the other hand, believes the shaft of loose hair, because of its scales with chisel-like root ends, inserts into the depth of the natal cleft in the midline of sacrococcygeal area. Friction forces and skin vulnerability help this step of hair insertion. Once one hair inserts successfully, other hairs can insert more easily. Foreign body tissue reaction and infection follow, and the primary sinus of pilonidal disease forms. Secondary openings often occur because of the self-propelling ability of hair to burrow through the skin, or spontaneous rupture of the abscess. The secondary openings have a different appearance from the primary midline ones in that they are marked by elevations of granulation tissue and discharge of seropurulent material. Hairs, if seen, sticking out of the secondary opening are in the abscess cavity that the body tries to spit out. ${ }^{8}$

Unusual locations of pilonidal sinus, such as the umbilicus, a healed amputation stump, and interdigital clefts, and the recurrence of the disease in an adequately excised area support the acquired theory of this disease particularly Karydakis's concept of hair insertion.

Most sinus tracts (93\%) run cephalad; the rest (7\%) run caudad and may be confused with a fistula-in-ano or with hidradenitis suppurativa. ${ }^{9}$

Treatment of pilonidal sinus can be done in one of several ways: non operative treatment, lateral incision and excision of midline pits, incision and marsupialization, wide local excision with or without primary closure, excision and Z-plasty, or advancing flap operation (Karydakis procedure).

Karydakis procedure:

Karydakis designed an operative technique to abolish risk factors. A "semi lateral" excision is made over the sinuses all the way down to the presacral fascia. Mobilization is carried to the opposite side so that the entire thick flap can be advanced toward the other side on closure. A closed suction drain is placed. This technique avoids the midline wound. 10

In a series of 7471 patients who received the advancing flap procedure, the complication rate was $8.5 \%$, mainly infection and fluid collection. The mean hospital stay was three days, with many patients requiring one day hospitalization or the procedure performed on an outpatient basis. The recurrence rate was $1 \%$, with follow up ranging from 2 to 20 years. In each recurrence, reinsertion of hairs was observed. The Karydakis flap procedure has proved to be effective, $8,11,12$ but it is a moderately extensive procedure.

\section{Bascom's flap (cleft lift):}

This unique method for treating the unhealed wound was devised by Bascom. ${ }^{13}$ The basic concept is to excise the unhealed skin and the underlying subcutaneous tissue. The natal cleft is eliminated by replacing the defect at the depth of the cleft with a skin flap over the wound. This operation is easier than it appears and is less extensive than other types of flaps. The subcutaneous fat is not mobilized. The flap is a full thickness skin flap. The procedure is performed with the patient under general or spinal anesthesia. A broad-spectrum antibiotic is administered when the patient is called to the operating room and continued until the drain is removed four to five days later. The patient is placed in the prone jack knife position. With the patient's buttocks pressed together, the lines of contact of the cheeks of the buttocks are marked with a felt-tipped pen. The cheeks of the buttocks are then taped apart, and the skin is prepared and draped.

The skin in this region is infiltrated with $0.25 \%$ bupivacaine (Marcaine) containing 1:200,000 epinephrine to decrease bleeding. A triangle-shaped section of skin overlying the unhealed wound is excised, extending above and lateral to the apex of the cleft. The lower end of the incision is curved medially 
toward the anus to avoid a "dog-ear" upon closure. The granulation tissue and hairs are removed. No fat or muscle is mobilized. After the skin flap (dissected only into the dermis) is raised out to the previously marked line on the left side, he scrubbed out abscess cavities with gauze. He slices scar and abscess walls to release tense contractures but leaves scar fragments in place, attached to fat, to ensure blood supply. ${ }^{14}$

Then the tapes are released. The skin flap is positioned to overlap the edges of the wound on the right side. The excess skin is excised. A closed suction drain is placed in the subcutaneous tissue. The subcutaneous tissue is closed with 3-0 chromic catgut, and the skin is closed with subcuticular 3-0 synthetic monofilament absorbable suture. The suture line can be reinforced with a running suture, or Steristrips can be applied.

The key to this operation is to create the skin flap so that the suture line is off the midline. It should be noted that Bascom described this technique to treat unhealed wound or recurrent pilonidal sinuses, although it is possible to use it for a complex primary disease.

\section{Patients and methods:}

Sixty eight consecutive patients with chronic natal cleft pilonidal sinuses seen over a period of 15 months (January 2012 to March 2013) were included in this prospective study. The ages of the patients ranged from 16 to 38 with a mean age of 24.4 years. There were 44 males and 24 females with a male / female ratio of 1.8:1. Sixty patients had de novo sinuses with no previous attempt of surgical treatment, and 8 patients (11.8\%) had recurrent sinuses following previous surgical treatment with excision and primary midline closure. All recurrences occurred within 2 years after the first surgery.

\section{Surgical technique:}

In this study, operations in 24 cases were done under spinal anesthesia and the other 10 cases under general anesthesia. With induction of anesthesia; I.V. dose of Augmentine 1.2 gm vial was given. Patient was positioned in prone jack knife position. The pelvic girdle was supported and raised with a soft pillow. While pressing both buttocks against each other; a marking pen was used to delineate the line of contact between both buttocks from above the natal cleft, down to a level opposite anal verge. Then both buttocks were tapped apart to expose the natal cleft. Povidone iodine $10 \%$ was used as skin antiseptic.

In this study we preferred to inject adrenaline $1 / 200,000$ into subcutaneous plane to facilitate bloodless dissection of sinus tracts. Also, we preferred not to use methylene blue injection into sinus tracts.

The previous marking lines were considered the guide for incision and the limiting border for operative dissection. The incision was carried down on the line on left side. Incision was about $5-7 \mathrm{~cm}$ in length "usually upper point $2 \mathrm{~cm}$ above the level of upper sinus pit passing downward to a point $1 \mathrm{~cm}$ below the level of lower sinus pit”. It was advisable not to go beyond the coccygeal tip. A curved incision starting from the upper point to the lower point passing $0.5-1 \mathrm{~cm}$ to the right side of the pilonidal sinus pits was made.

The incision was deepened about $1 \mathrm{~cm}$ into the subcutaneous fat then started to go medially to dissect directly around the fibrotic tract. In the circumstances of bloodless field; a clear view of the whitish fibrotic tract was obtained.

The aim of dissection here was to minimize excision of healthy nearby tissues to a minimal degree. In all cases we did not reach the presacral fascia. The dissection was limited around fibrous tract of pilonidal sinus. This dissection was carried out by coagulating diathermy.

In branched pilonidal sinus or laterally placed external opening, the incision was modified by adding extension limb or V-cut in the direction of this sinus opening or branch.

After completing the elliptical excision of pilonidal sinus tract; we started to create an advancement flap from the right border of the wound. Undermining of skin flap was done creating a flap thickness $0.7-1 \mathrm{~cm}$ "skin and subcutaneous fat". The limiting border of dissection was the marking line. Opposite 
this limiting border, a deep cut was done through gluteal fat to reach and divide the fascia covering the gluteus maximus muscle. Then we started to dissect the fascia back from its muscle towards the midline to a degree that allowed a tension free eversion of this fascio-fatty flap. Suturing of the everted fascia to the fibro-fatty tissues of the left side was done. This last step allowed filling of the natal cleft "cleft lift" and also exposed area of muscle surface and subfascial plain with a rich lymphatic drainage "internal drainage".

Hemostasis was checked for any bleeding points and dealt with by coagulation diathermy. Subcutaneous tube drain was inserted in the wound bed through a different stab away from midline. A purse string suture was placesd around the point of drain exit and held without tie. The plaster tape was released then the wound was closed in two layers. First layer was inverted deep dermal stitches using Vicryl 3-0 sutures. The second layer was interrupted vertical mattress suture by Prolene 3-0 sutures. The suture line was sited over previous left marking line. The new cleft became obviously shallow cleft. The wound was totally placed in exposed area away from deep moist cleft.

After complete closure of skin; the tube drain was connected to suction machine to induce sutureless collapse of cavity. Then, a firm dressing was applied over operative area with on table removal of drain and simultaneously tightening the purse string suture.

All patients were allowed for overnight stay and were discharged after 24 hours. Postoperative pain control was achieved by oral Paracetamol and NSAID.

Patients were scheduled for postoperative follow up visits at outpatient clinic on $5^{\text {th }}$ and $12^{\text {th }}$ days. Stitches were removed on $12^{\text {th }}$ postoperative day. Further follow up visits are scheduled after 3 and 6 months later.

\section{Results:}

The main complaint of all the patients was mild pain and discomfort in the sacral region, with a chronically discharging sinus or sinuses. A single sinus was present in
34 patients, multiple midline sinuses were present in 26 patients, and lateral sinuses in 8 patients. In the 8 cases with lateral sinuses, all were recurrent cases and the eighth case with lateral sinus was type I DM. The operative time ranged from 40 to 80 minutes, with a mean operative time of $56.5 \pm 3.3$ minutes.

All cases were admitted for 24 hours and discharged safely without delay in the $1^{\text {st }}$ postoperative day. No cases required readmission for any reason.

Only 4 patients (5.9\%) developed wound seroma detected on the $5^{\text {th }}$ day at the first wound inspection, which required simple aspiration through wide bore needle.

Postoperative pain control with oral Paracetamol and NSAIDs was satisfactory and sufficient for all patients. All patients with recurrent diseases reported less postoperative pain compared to the previous surgery.

All cases attended outpatient clinic on the $12^{\text {th }}$ postoperative day with nice wound healing and stitches were removed successfully. All patients attended the 3 months and 6 months follow up period with no recurrences.

In one case known as type I DM; the pilonidal sinus tract was Y-shaped. Right limb ended with skin sinus while left limb ended as blind track in the subcutaneous tissue. The common stem contained multiple midline sinuses. The incision in this case was modified by adding a V- cut incision to involve the right limb while the left limb was easily excised after extension of incision towards the right side. This case experienced post-operative wound seroma which required simple needle aspiration every other day for 4 times.

\section{Discussion:}

In 1992, Dr. George Karydakis published the largest personal series in the world. ${ }^{10} \mathrm{He}$ excised the sinus with a simple biconvex elliptical incision, only just crossing the midline to excise the sinus down to the sacrum. A thick flap of skin and subcutaneous tissue was then created. This flap was advanced across the midline to meet the other side of the wound with two layers of catgut sutures 


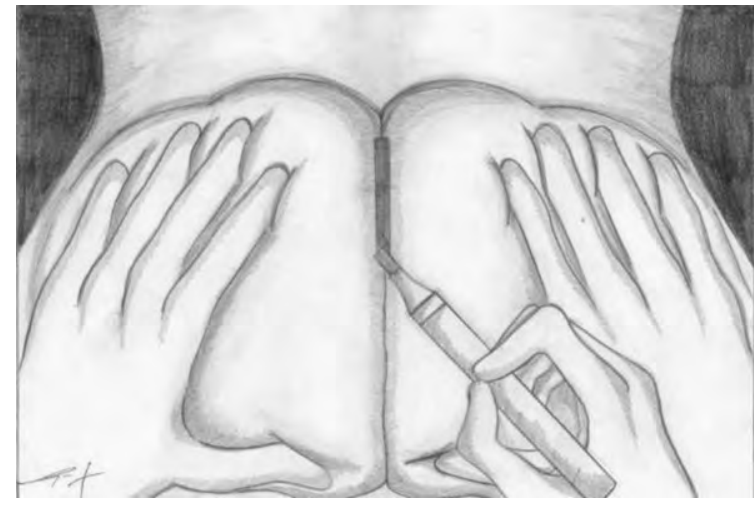

Figure (1): Drawing natal cleft border.

Drawing done by my clinic Filipino nurse:

Gian C. Victoria.

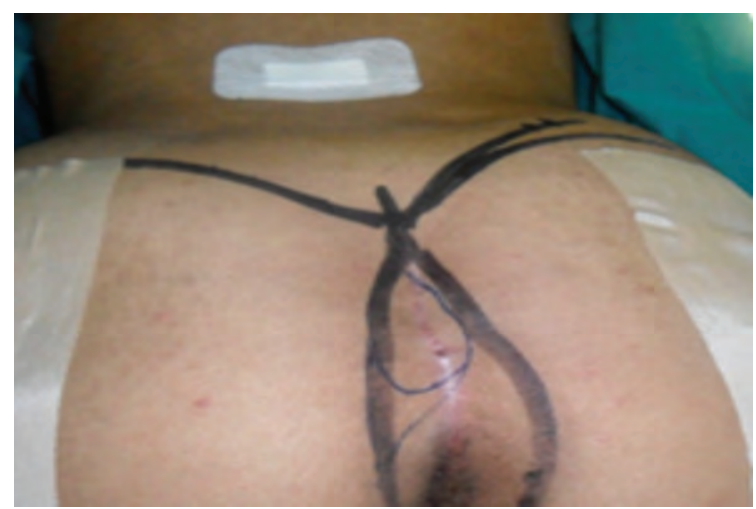

Figure (3): Incision line "blue line”, done toward left side.

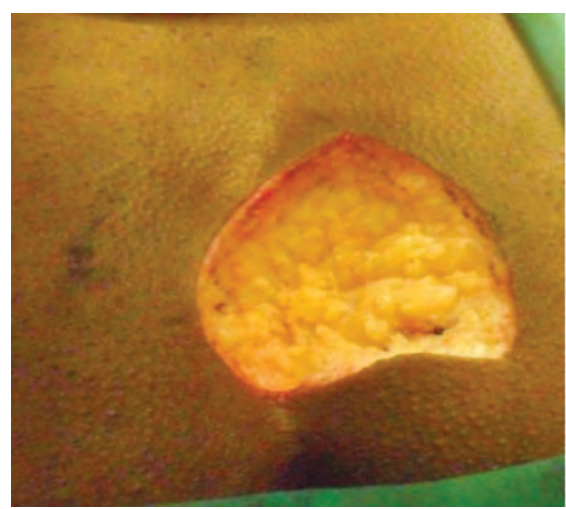

Figure (5): After excision of pilonidal sinus track.

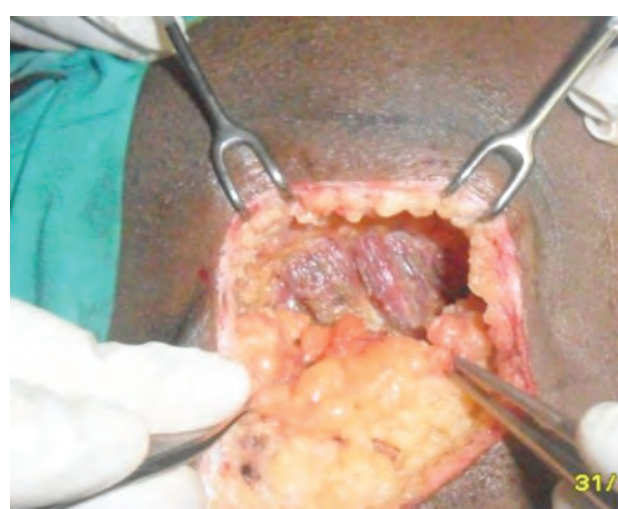

Figure (7): Exposure of gluteus maximus muscle.

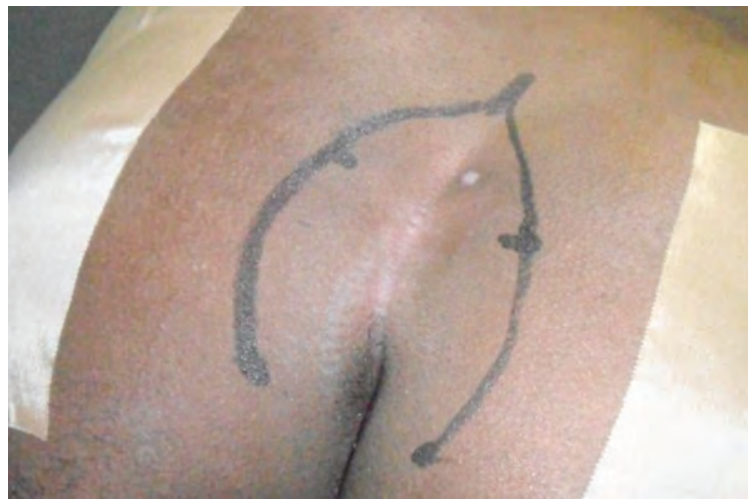

Figure (2): Limiting border of natal cleft.

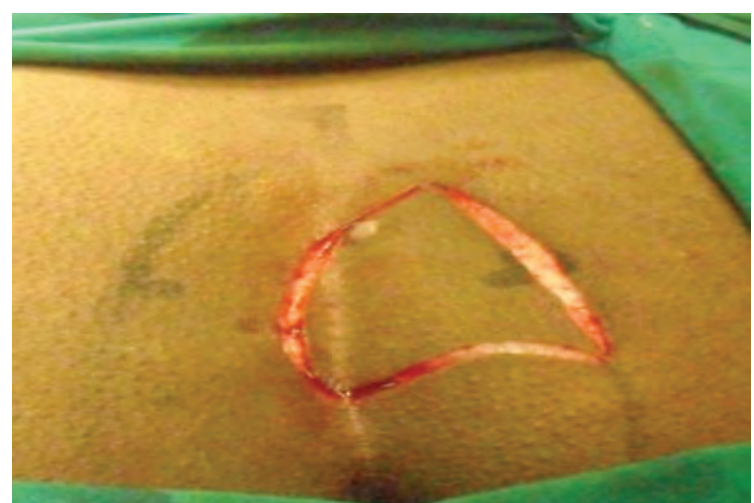

Figure (4): Incision line done toward right side due to right sided pilonidal sinus opening.

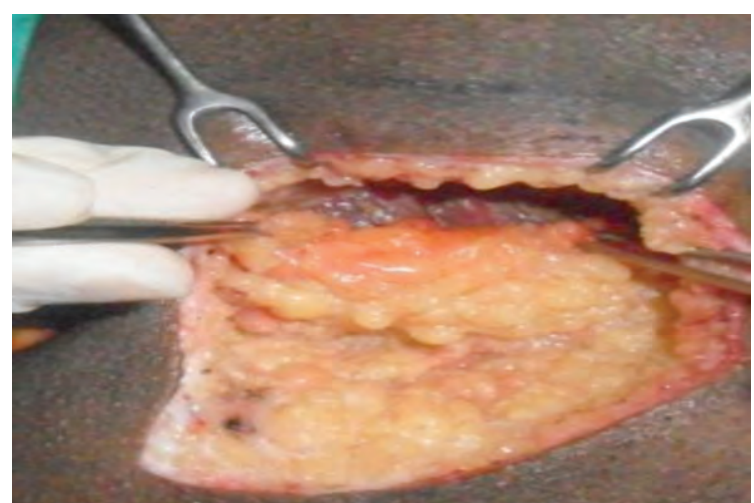

Figure (6): Creating fasciofatty flap.

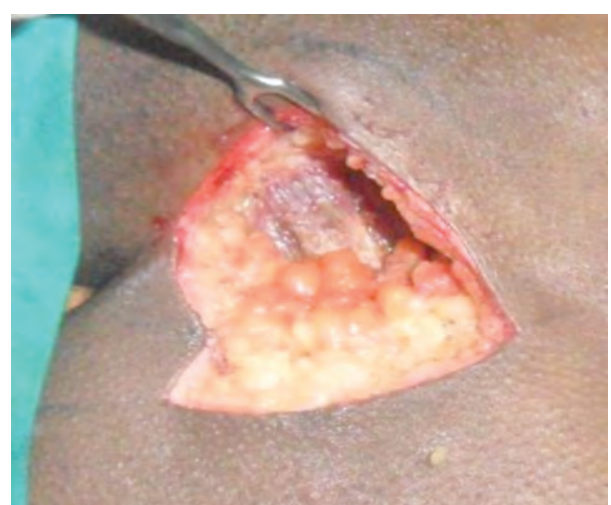

Figure (8): Eversion and fixation of fasciofatty flap "filling of natal cleft". 


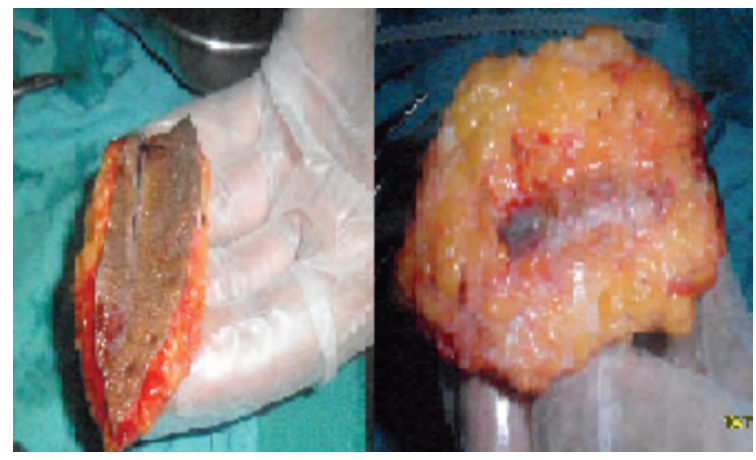

Figure (9): Excised specimen skin view and undersurface view showing fibrous tract contain blackish content "hair".

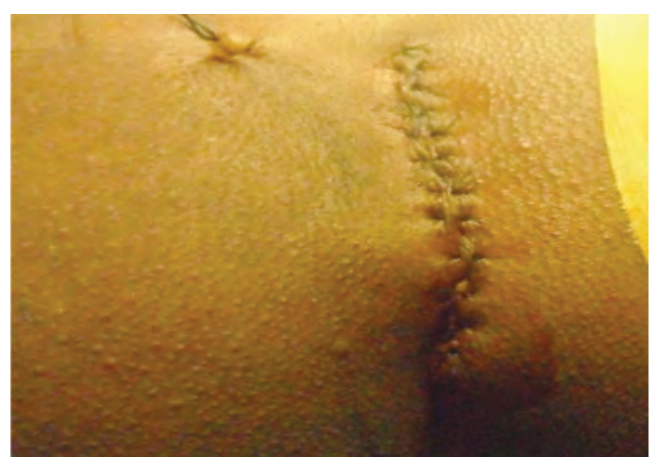

Figure (11): On table drain removal. Off midline wound, toward right side.

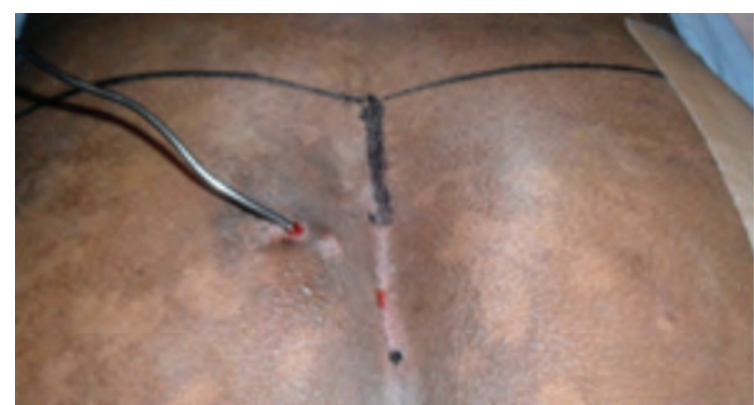

Figure (13): Branched pilonidal sinus with lateral opening.

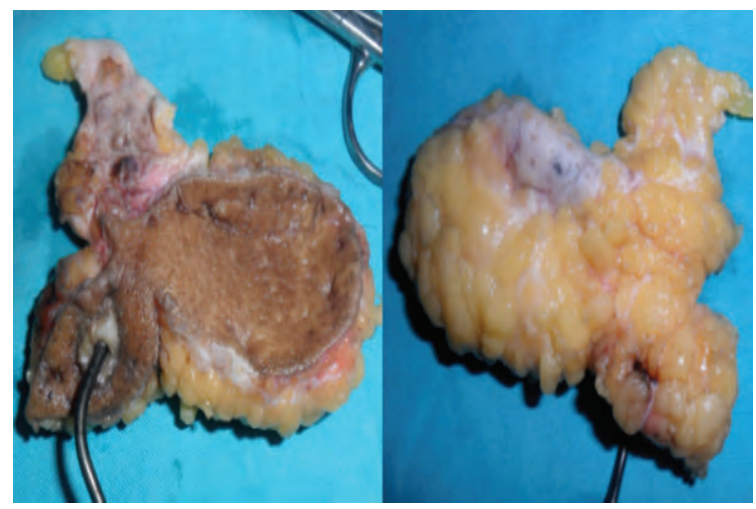

Figure (15): Excised Y-shaped sinus tract.

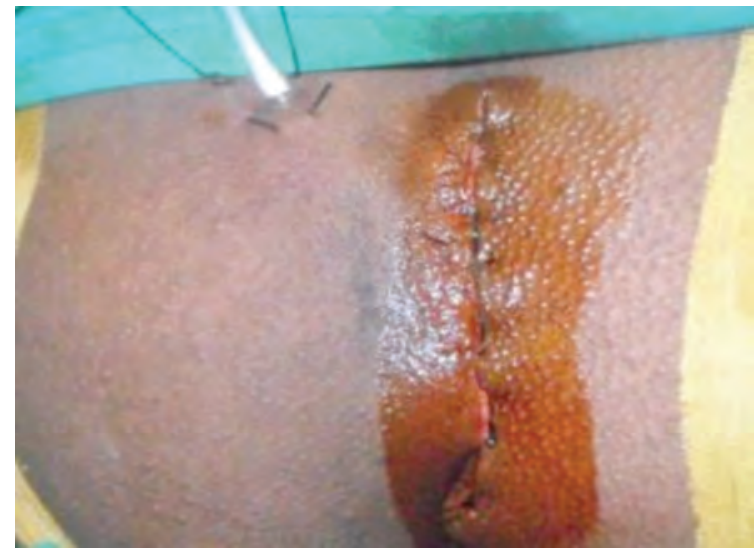

Figure (10): Drain insertion and wound closure. Notice purse string suture around drain exit.

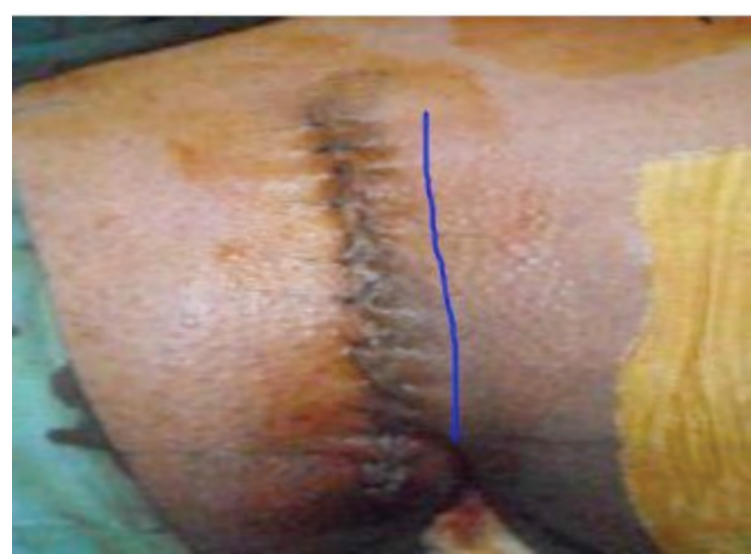

Figure (12): Off midline wound toward left side.

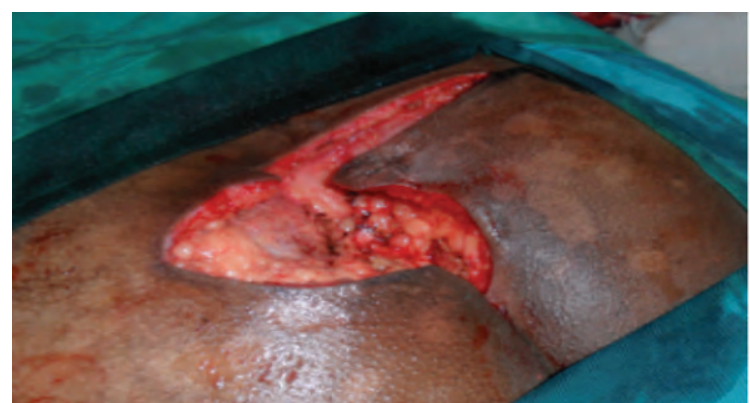

Figure (14): Modified incision for branched pilonidal sinus.

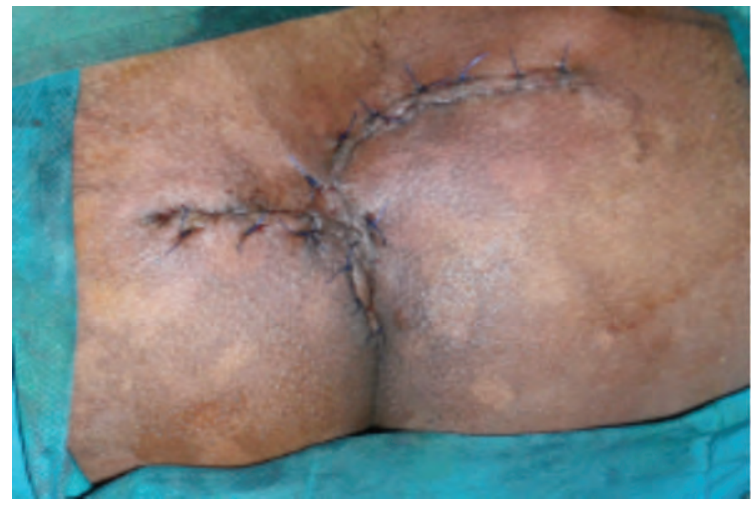

Figure (16): Modified incision after skin closure. 


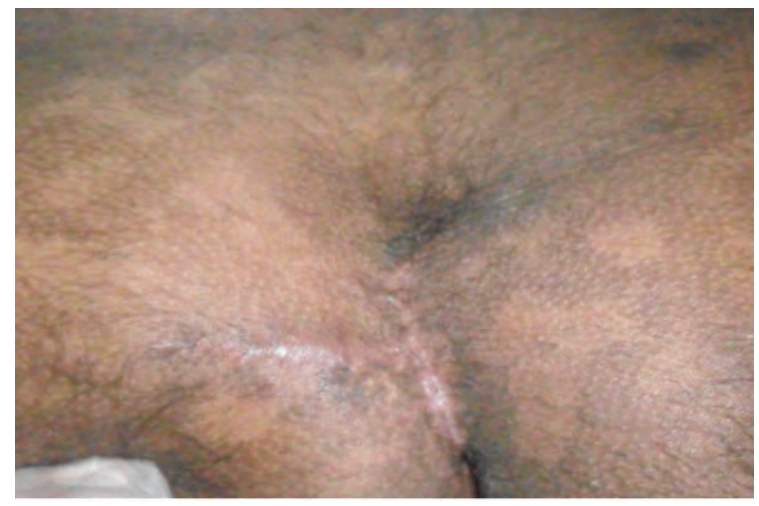

Figure (17): 6 months post operative follow up; complete healing and no recurrence.

Table shows comparative points between the three different techniques for operative treatment of pilonidal sinus.

\begin{tabular}{|c|c|c|c|}
\hline & Karydakis technique & Bascom technique & New technique \\
\hline \multirow[t]{2}{*}{ Incision } & \multirow{2}{*}{$\begin{array}{l}\text { Semilateral elliptical } \\
\text { incision }\end{array}$} & \multicolumn{2}{|c|}{ Over one limb of natal cleft border } \\
\hline & & $\begin{array}{l}\text { Completed as } \\
\text { triangular skin incision }\end{array}$ & $\begin{array}{l}\text { Completed as } \\
\text { elliptical incision } \\
\text { around sinus pits. }\end{array}$ \\
\hline Resultant wound & \multicolumn{3}{|c|}{ Off-midline skin wound } \\
\hline Depth of dissection & $\begin{array}{l}\text { Down to presacral } \\
\text { fascia. }\end{array}$ & Sub-dermal plane. & $\begin{array}{l}\text { Dissection plane at } \\
\text { about } 1 \mathrm{~cm} \text { depth. }\end{array}$ \\
\hline Flap thickness & $\begin{array}{l}\text { Thick (skin + full } \\
\text { thickness S.C. fat). }\end{array}$ & $\begin{array}{l}\text { Very thin (skin only } \\
\text { flap). }\end{array}$ & $\begin{array}{l}\text { Thin (skin }+ \text { splitted } \\
\text { S.C. fat) }=7-10 \mathrm{~mm} \text {. }\end{array}$ \\
\hline How to obliterate & \multicolumn{3}{|c|}{ Through bridging of skin flap \pm S.C. tissue over natal cleft. } \\
\hline natal cleft? & \multicolumn{2}{|c|}{ 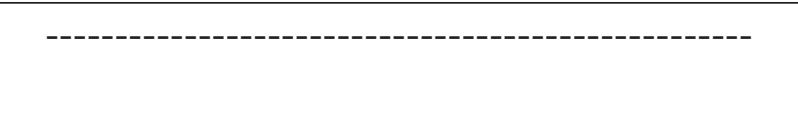 } & $\begin{array}{l}\text { +filling of defect by } \\
\text { fascio-fatty flap. }\end{array}$ \\
\hline Drain & \multicolumn{2}{|c|}{ Closed suction drain. } & No external drainage. \\
\hline Sinus tracts & Excised & $\begin{array}{l}\text { Opened, granulation } \\
\text { tissue is scrubbed out } \\
\text { and slicing of scar } \\
\text { tissue in place. }\end{array}$ & Excised \\
\hline Complications & $\begin{array}{l}\text { 8.5\% “infection \& } \\
\text { fluid collection” }\end{array}$ & $\begin{array}{l}33 \% \text { :infection \& } \\
\text { wound failure” }\end{array}$ & $\begin{array}{l}\text { 5.9\% “mild seroma } \\
\text { treated with simple } \\
\text { aspiration". }\end{array}$ \\
\hline Healing time & 14-20 days & 28 days & 12 days \\
\hline Recurrence & $1 \%$ & $8 \%$ & $\begin{array}{l}\text { No recurrence yet } \\
\text { "may be due to low } \\
\text { number of cases \&/ } \\
\text { or 0nly } 6 \text { months } \\
\text { follow up." }\end{array}$ \\
\hline Follow up & 2-20 years & & 6 months \\
\hline
\end{tabular}


to the fat. The wound was then closed with skin sutures with suction drainage. ${ }^{14,15}$ Using this technique he reported a recurrence rate of less than $1 \%$. He attributed those recurrences to hair reinsertion. ${ }^{10}$ The same results of Karydakis were reproduced by others, with a hospital stay ranging from 4 to 16 days. ${ }^{16-19}$

In spite of his good results, Karydakis has described the following difficulties during his procedure:

1- Difficulty in fixing the flap was found to be due to stitch cutting out of the loose fat on the side of the flap. ${ }^{10,16}$

2- The complication rate has remained high (8.5\%). These were mainly due to infection and fluid collection. ${ }^{10,16}$

3- It was observed that as young people developed adult body form, there was a change in the skin of the mid-line, following Karydakis operation. The skin in the depth of the "new" natal cleft developed the characteristics of a vulnerable raphe, with wide pores and maceration. ${ }^{10,16}$

Bascom's technique is a day case surgery, which can be done under local anesthesia, which similarly places the main wound away from the midline. He reported an average time of healing of 4 weeks and a recurrence rate of $8 \% .{ }^{17,7,20}$ Another modification reported also by Bascom is the cleft closure technique. ${ }^{17,21,22}$ A thinner subcutaneous flap is used to shift the scar off the midline. Bascom technique is to scrub out abscess cavities with gauze. He slices scar and abscess walls to release tense contractures but leaves scar fragments in place, attached to fat, to ensure blood supply. ${ }^{22}$

The procedure is simpler than the original Karydakis technique, and may be done under local anesthesia as a day case procedure but with a high incidence of wound failure and only in $33 \%$ of cases the wound healed primarily. ${ }^{17}$

In our study; the planned incision line puts the final skin wound over the top of gluteal region away from moist natal cleft. This offered a good dry environment for wound healing without wound maceration, anaerobic infection and finally wound failure and disruption.

The created flap (7-10 mm) was not as thick as Karydakis flap and this gave the flap more strechability. On the other hand; also it was not very thin as Bascom flap and this made the flap stronger and of more reliable blood supply.

Dissection was limited to around the wall of the fibrous track of pilonidal sinus. This limited dissection made less tissue loss and resulted in less wound cavity and subsequent less seroma formation.

The creation of fasciofatty flap opens the subfascial plane with its high lymphatic drainage, this is suspected to abolish the need for wound drainage with decreased incidence of seroma complication and wound disruption.

The created fasciofatty flap also gives mechanical filling of the natal cleft with subsequent obvious reduction in natal cleft depth.

Eversion of fasciofatty flap allows the stitches to be taken in the fascia rather than the fat. The fascia holds stitches better and therefore holds the flap better and this leads to reliable filling of natal cleft. This technique takes a middle pathway between Karydakis and Bascom flap techniques. It carries advantage of Karydakis technique in complete excision of pathological tissues. Also, it is equal to Bascom technique in the simplicity of flap dissection and limited tissue excision with preservation of nonpathological tissues. But I think that this new technique provides a further step in advantage of simplicity, pathology eradication, natal cleft lift and minimal tissue excision. In this technique; the external drainage is replaced by internal drainage through muscle surface and subfascial plane.

A longer period of follow-up is needed to confirm the previously mentioned benefits; the new technique is still a simple one which is suitable for de-novo as well as recurrent and complex cases after addition of suitable modification of skin incision.

It is also suitable for day case surgery since no drainage is needed and the pain was easily controlled with oral non-steroidal drugs. 
In our study; none of the patients developed wound infection. All wounds healed primarily. The only disadvantage noticed by the operator was that in cases with branched pilonidal sinus; which needed relatively wider area of dissection, these cases developed seroma which required multiple simple needle aspiration every other day for 3-4 successive times.

In spite of the initial promising results of this study, more studies on a larger number of patients, with longer follow up period are recommended to assess the value of this new technique.

\section{References:}

1- Anderson AW: Hair extracted from an ulcer. Boston Med Surg J 1847; 36: 74.

2- Hodges RM: Pilonidal sinus. Boston Med Surg J 1880; 103: 485-486.

3- Buie LA: Jeep disease. South Med J 1944; 37: 103-109.

4- Abramson DJ: Outpatient management of pilonidal sinuses: Excision and semiprimary closure technic. Mil Med 1978; 143: 753-757.

5- Kooistra HP: Pilonidal sinuses. Review of the literature and report of three hundred fifty cases. Am J Surg 1942; 55: 3-17.

6- Lord PH: Etiology of pilonidal sinus. Dis Colon Rectum 1975; 18: 661-664.

7- Bascom J: Pilonidal disease: Origin from follicles of hairs and results of follicle removal as treatment. Surgery 1980; 87: 567-572.

8- Karydakis GE: Easy and successful treatment of pilonidal sinus after explanation of its causative process. Aust N Z J Surg 1992; 62: 385-389.

9- Notaras MJ: A review of three popular methods of postanal (pilonidal) sinus disease. Br J Surg 1970; 57: 886-890.

10-Petersen S, Koch R, Stelzner S, Wendlandt TP, Ludwig K: Primary closure techniques in chronic pilonidal sinus: A survey of the results of different surgical approaches. Dis Colon Rectum 2002; 45: 1458-1467.

11-Kitchen PRB. Pilonidal sinus: Experience with the Karydakis flap. Br J Surg 1996; 83: 1452-1455.

12-Akinci OF, Coskun A, Uzunkoy A: Simple and effective surgical treatment of pilonidal sinus. A symmetric excision and primary closure using suction drain and subcuticular skin closure. Dis Colon Rectum 2000; 43: $701-707$ (commentary by Bascom $\mathrm{J}$ in 706-707).

13-Bascom JW: Repeat pilonidal operations. Am J Surg 1987; 154: 118-122.

14-Bascom J, Bascom T: Utility of the cleft lift procedure in refractory pilonidal disease. The American Journal of Surgery 2007; 193: 606-609.

15-Edwards MH: Pilonidal sinus: A 5years appraisal of the Millard - Lord Treatment. Br J Surg 1977; 64: 867-868.

16-Kitchen PRB: Pilonidal sinus - improving the Karydakis operation. ANZ J Surg 2006; 76 (Suppl. 1): A31.

17-Senapali A, Cripps N: Pilonidal sinus. Recent Advances of Surgery 2000; 23: 33-42.

18-Anyanwu AC, Hossain S, Williams A, Montgomery AC: Karydakis: Operation for sacrococcygeal pilonidal sinus disease: Experience in a district general hospital. Ann R Coll Surg Engl 1998; 80: 197-199.

19-Mann CV, Springall R: 'D' excision for sacrococcygeal pilonidal sinus disease. $J$ R Soc Med 1987; 80: 292-295.

20-Bascom J: Pilonidal disease: Long term results of follicle removal. Dis Colon Rectum 1983; 26: 800-807.

21-Bascom J: Pilonidal sinus: Current therapy in colon and rectal surgery. New York: Dekker (Publisher);1990; p.32-39.

22-Bascom J U: Pilonidal sinus. Curr Pract Surg 1994; 6: 175-180. 